\title{
Design and Implementation of Axial Flux Induction Motor Single Stator - Single Rotor for Electric Vehicle Application
}

\author{
M. Ashari ${ }^{1}$, H. Suryoatmojo ${ }^{1}$, D. Candra R. ${ }^{1}$, R. Mardiyanto ${ }^{1}$, D. Fahmi ${ }^{1}$, K. B. Adam $^{1}$, and S. Hidayat ${ }^{1}$
}

\begin{abstract}
In the application of a reciprocating compressor failures are often caused by valve malfunction. The failure can be minimized by a proper valve design. This research described an experimental study to investigate characteristics of vibration and cylinder chamber pressure diagrams, as results of open-close valve processes in a single-stage, single-acting air reciprocating compressor. Vibration and pressure were measured at the same crank angle. The modification was materialized by a change in a valve seat profile of a discharge side. The study was conducted for several working loads. Compared to the discharge valve which was (commonly) supplied by the manufacturer, the result showed that a provision of a taper angle on a discharge valve seat would decrease vibration level, made longer discharge opening, and would increase discharge pressure.
\end{abstract}

Keywords — reciprocating compressor, valve seat, vibration, pressure.

\section{INTRODUCTION}

$\mathrm{V}$ arious researches have been done to develop electric vehicles in order to satisfy human needs, as vehicles with fuel in general. One of existing problems in the design of electric vehicles is on the Energy and Power Density. This problem also indirectly related to the size and weight of the vehicle. Along with the vehicle design that more concise and complex, room for electric motor placement in the vehicle is very limited, so electric motor which is efficient in size is needed.

To solve previous problems, there is an idea to make electric motors (especially induction motors) with axial flux method. With Axial Flux Induction Motor (AFIM), the construction of electrical motors that is slimmer than conventional motors become possible, because the stator and rotor facing each other (flux radial method) rather than lengthwise tubular shape of conventional induction motors. By utilizing the axial flux electric motor to drive the car, the installation of the electric motors will be easier.

\section{AXIAL FLUX INDUCTION MOTOR}

\section{A. AFIM}

In general the Axial Flux Induction Motor (AFIM) have the same working principle with induction motor (Radial Flux Induction Motor or often abbreviated RFIM), but the design is very different.

The most fundamental difference is magnetic flux direction.Magnetic flux generated of RFIM system is radial direction for machine axis. Whereas the magnetic fluxgenerated of AFIM system have axial direction for machine axis.

History records the first electric machine using axial flux system with electromagnetic induction principle. In 1821, Faraday introduced primitive disc machine is the forerunner of axial flux machines (AF machines). In 1831, Davenport claimed his hold patent of radial flux

${ }^{1}$ M. Ashari, H. Suryoatmojo, D. Candra R., R. Mardiyanto, D. Fahmi, K. B. Adam, and S. Hidayat are with Departement of Electrical Engineering, Faculty of Industrial Technology, Institut Teknologi Sepuluh Nopember, Surabaya, 60111, Indonesia. E-mail: suryomgt@ee.its.ac.id. machines (RF engine). The next radial flux motor dominates motors utilization of the world until this time.

\section{B. One stator - One rotor AFIM}

Design of one stator and one motor is the simplest design of axial flux induction motor. Form consists of only one piece of the stator and the rotor pieces. Flux starting from the stator moves toward the rotor and then back again to the stator. Because it consists of one stator and one rotor only, the torque produced is also smaller than AFIM using two stator ot two rotor systems.

\section{MOTOR DESIGN}

For design an axial flux induction motor. The first motor parameters must be specified as a target to be achieved. The following motor parameters to be made:

Power $=500$ watts

Number of phase $(\mathrm{m})=3$

$\mathrm{VPH}-\mathrm{ph}=100 / 58 \mathrm{~V} \mathrm{Y} / \Delta$

Pole $(\mathrm{p})=4$

Frequency $=50$

Power factor $($ estimated $)=0.8$

Efficiency $($ estimated $)=0.6$

From the target data above we can calculate the requirement specification needs supporters , both mechanically and electrically.

\section{A. Early Initialization motors Dimension}

To construct an electric engine we must determine the approximate dimensions/sizes of some parts of the machine as a reference for further calculations. In the picture below which shows the cross section of the stator or rotor without slots of AFIM.

Based on research by Campbell (1974) mentioned that for axial flux induction motor with a comparison between De and DSE that the resulting optimal torque is 0.58 . To limit the surface area in the axial flux motors specified outer diameter (Dse) is the first $18 \mathrm{~cm}$ or $0.18 \mathrm{~m}$ . Thus we can get the value of Ds from

$\mathrm{K}_{\mathrm{d}}=\frac{\mathrm{Ds}}{\mathrm{Dse}}=0,58$

It can be calculated :

Rin (inner radius) $\quad=0,5 \times$ Ds

Rout (outer radius)

$=0,5 \times$ Dse

core length (le)

= Rout-Rin 
Rave (average radius) $=\sqrt{ }($ Rout. Rin $)$

Surface area which produces force / torque (Sr)

$\mathrm{S}_{\mathrm{r}}=\Pi\left(\right.$ Rout $\left.^{2}-\mathrm{Rin}^{2}\right)$

\section{B. Characteristics of Core Materials}

In this study using different types of materials on the market and affordable that is steel type ST37. ST37 has the composition of a mixture of iron (Fe) with various other metals according with the following table 1 . From the curve in Figure 4 shows that for B at 0 to 1.4 Tesla, material has a permeability $(\mu)$ that relatively similar.

\section{Selection of Magnetic load}

Magnetic load is the maximum flux density (B) that generated by the core to produce a turning force. The flux density will affect the amount of magnetic flux generated by the core. Simply put the amount of flux is the product of the flux density with the flux-producing area.

$$
\phi=\int_{A} B d A
$$

Figure 5 below explain that calculation of the flux density at AFIM is oparated at each level of diameter, the core is divided into 10 sections circularly $\mathrm{n} 1 \ldots . . \mathrm{n} 10$ with a difference of $0.4 \mathrm{~cm}$ radius.

$$
\mathrm{B}_{\mathrm{ds}(1 \ldots n)}=\frac{B \delta . \tau \mathrm{s}_{(1 \ldots \mathrm{n})}}{\tau \mathrm{s}_{(1 \ldots \mathrm{n})}-b s}
$$

$$
\begin{array}{ll}
\mathrm{Bds}(1 \ldots \mathrm{n}) & =\text { flux density at the core } \\
\mathrm{B} \delta & =\text { flux density at the air gap } \\
\tau \mathrm{S} & =\text { Distance between the stator slot } \\
\mathrm{bs} & =\text { width of stator slot }
\end{array}
$$

The flux density at the air gap of 0.6 selected in these session, table 2 recapitulate of flux density at the core of stator.

Based on table 2, Flux density at the core position should be located before the saturation. From magnetisation curve, flux density at the core can be obtaned by a material before saturation phase, so that flux density at the air gap $(B)=0,6$ can be applied.

\section{Stator Design}

1) Determination The Number of Slot

The Motor use 3 phase source and 4 pole, therefore the minimal number of the pole is $3 \times 4=12$ slot. AFIM design use 12 slot and it minimize production motor cost, if it is so many slot then the production cost will so expensive and the complication so high.

\section{2) Stator Winding}

Fluks $\Phi$ is the product of the flux density (B) with fluxproducing area. The wide area here is surface wide area per one pole ( 1 pole pitch). On draft AFIM has 4 poles so that the area

$$
\mathrm{S}=\mathrm{Sr} / \mathrm{p}
$$

$\mathrm{Kw}$ value Or winding factor is determined by the distribution factor $(\mathrm{Kb})$ and the pitch factor $(\mathrm{Kp})$

$\mathrm{Kw}=\mathrm{Kb} . \mathrm{Kp}$

$\mathrm{Kb}=\frac{\sin m \gamma / 2}{m \sin \gamma / 2}$

$\mathrm{Kp}=\cos \theta_{\mathrm{sp}} / 2$

Voltage is induced in the stator phase-neutral voltage is reduced by the loss of copper loss (R), the empirical Eind is $97 \%$ of V ph-n. Then be obtained,

$$
\mathrm{N}=\frac{\text { Eind }}{4,44 \mathrm{f} \Phi \mathrm{Kw}}
$$

\section{E. Current Requirenment Calculation}

In electric load power will increase proportional to the increase in electric current (voltage fixed). Estimates of current required if the star is linked,

$$
I=\frac{P}{\sqrt{3} \times V \times \operatorname{Cos} \varphi \times \eta}
$$

\section{F. Requirement torque Analysis and load current}

Energy in rotational motion is the result of multiplying the torque by the angular velocity.

$\mathrm{P}=\tau \omega$

At this axial flux motors angular velocity is

$\mathrm{ns}=\frac{120 \mathrm{f}}{\mathrm{p}} \mathrm{rpm}$

Taking the estimated slip $=6 \%$ then the rotational rotor speed of $1400 \mathrm{rpm}$.

$\mathrm{nr}=\mathrm{ns}-(\mathrm{s} \times \mathrm{ns})$

$\omega=\operatorname{nr} x \frac{2 \pi}{60} \mathrm{rad} / \mathrm{s}$

torque is the turning force which directly proportional to the length of the arm, so as torque is multiplication between the resulting force in air gap (tangensial stress), the rotor radius and surface area.

$\tau=\mathrm{S}_{\mathrm{r}} \mathrm{R}_{\mathrm{ave}} \sigma \mathrm{Ftan}$

accordingly,

$\sigma$ Ftan $=\frac{\tau}{R_{\text {ave }} S r}$

thereafter, with the known specification before, total conductor can be known with the derivative tangensial equation,

$\sigma \mathrm{Ftan}=\frac{B \cdot A}{2}$

Linear current density (A) can be obtained.

Afterward the current which flow in the conductor can be obtained from the A value,

$Z=2 \cdot m \cdot N$ (total conductor in three phase)

$\mathrm{D}=$ Average Diameter $=2 \times \mathrm{R}_{\mathrm{ave}}$

$A=\frac{I \cdot Z}{\pi \cdot D}$

From the calculation above, the current flows in the stator. The current is equal with the force which is used to generate load torque needed. The current magnetization, current for mechanical torque, mechanical and iron losses are not included in the current value that can be obtained above. The current in this final project is $3,48 \mathrm{~A}$.

\section{G. Rotor Design}

The axial flux motors use a cage rotor system, rotor sections has a shape almost the same stator, which is a dish that also has a slot. On the rotor there are two types of material. That is as the aluminum rotor bar and St37 as core. Aluminum with a mixture having resistifitas between $2,82 \times 10-8 \Omega \mathrm{m}$ lower than the resistivity of steel is $1.18 \times 10-7 \Omega \mathrm{m}$, whereas the relative permeability of aluminum close to 1 . Permeability is very small compared with the relative permeability of the 
steel materials worth about 687. Number of slots in the rotor must adjust number of stator slots with the provisions particular to avoid the occurrence the problem as follows :

a. Rotor lock

Can be avoided with the provisions of $\mathrm{Ss} \neq \mathrm{Sr}$.

b. Crawling phenomena

Crawling phenomena is when a a rotating magnetic field is produced in the air gap and usually nonsinusoidal containing harmonics 5 and 7, Harmonics 7 will result in a dip in the torque and speed characteristics. This phenomena can be avoided with the provisions of $\mathrm{Ss}-\mathrm{Sr} \neq \pm 3 \mathrm{P}, \mathrm{Sr} . \neq$ 6PG, Sr $<1.25$ Ss (Ss = slot stator, rotor $\mathrm{Sr}=\mathrm{Slot}$ ).

c. Sound will be heard when spinning rotor (noisy operation)

This can be avoided with the provisions of Ss-Sr $\neq \pm$ $1, \pm 2,( \pm P \pm 1),( \pm P \pm 2)$.

Of some of the provisions of the above then by the number of stator slots 12 can be found a safe value for the rotor slot 9 .

After be known a rotor design, need be done checking a flux density in a rotor core. A Checking is done with an equal method in stator

$\mathrm{B}_{\mathrm{dr}(1 \ldots n)}=\frac{B \delta \cdot \mathrm{r}_{(1 \ldots \mathrm{n})}}{\tau_{(1 \ldots \mathrm{n})}-b r}$

$\operatorname{Bdr}(1 \ldots n)=$ a flux density in rotor core

$\mathrm{B} \delta=$ a flux density ini a air gap

$\tau \mathrm{r}=$ distance between a rotor slot

br = width a rotor slot

The result is as follows:

From a data result above so be ensured that a flux density in rotor core must below a saturation phase (B>1.4T).

\section{H. Yoke}

Yoke is a part of motor that function as a flux track back to initial way. Based on yoke position is divided become two type are yoke is put on a stator and yoke is put on a rotor. Yoke position is behind a part stator and rotor appropriate with figure 6. A yoke thickness can be calculated with formula

$\mathrm{Kf}$ is a flux density. A flux density at yoke (B) is determined appropriate with a material ability to generating magnet (magnetization curve) without occur a saturation condition. In this matter, be equated with a maximum flux density at stator core is 1,4 .

1) Air Gap

Between stator and rotor AFIM is found air gap, distance of this air gap very influence at rotor performance. In empirical, distance of optimal air gap can be calculate with formula as follows

$\operatorname{Lg}=3,06-\frac{6560}{\mathrm{D}+2280}$

$\mathrm{D}=$ Stator diameter in millimeters

\section{MOTOR CONSTRUCTION}

\section{A. Stator Construction}

In the process of making the stator, stator is divided into two parts : stator plae and core. These two parts are made separately. Core is made in three layers, total density of each layer are equal to $20 \mathrm{~mm}$. All of this three layers are attached to stator plate as shown in figure 7.Before assembly process, lamination process is done in the core, this lamination process using various method such as cleaner layers (stainless layer), thermostable paint, and iron glue which has epoxy material. All of this material have isolator characteristic. The purpose of the lamination process is to decrease eddy current loss.

After the process in stator has done, the winding can be place in the slot. The winding is formed before with particular mold, the specifications of the winding are 4 pole double layers, each pole has 50 coils, the dimension of the coil is determined before. Before the winding can be place, it must be coated with the film paper which separate and make intersection of the winding with the core body safe. Thereafter this copper winding is coated with thelamination liquid.

\section{B. Rotor Construction}

Rotor construction had similar with stator construction. Both of them have similar forms. The differences, rotor core didn't stand out form a slot but have flat form. Rotor have two parts, rotor bar and rotor core. Rotor bar made of aluminums material, and the rotor core made of steel ST37 materials.

When both of primary component have made, then we can do assembly process. It needs two poles to prop both of components.

\section{MOTOR TEST}

Equivalent circuit is needed to analyze induction motor. By using this equivalent circuit of induction motor, we can analyze torque curve to speed. To get equivalent circuit of induction motor, we have to do some test, such as: DC test, no load test, and block rotor test.

\section{A. DC Test}

DC test is purposed to measure the resistance of stator winding (R_1). At DC test, DC voltage variable as stator winding input for each phase,

$\mathrm{R}_{1}=\frac{\mathrm{V}}{\mathrm{I}}$

\section{B. DC Test}

No load test is purposed to know about the parameters of magnetizing current, core-loss, and to make sure that motor rotate. The Result of Measuring AFIM motor without load is shown in figure 5.

Current has reached nominal value before the nominal voltage reached, for no load test, then the parameter for the no load test taken from one of the test voltage. In this motor, the parameter taken at voltage value $15 \mathrm{~V}, 5,1 \mathrm{~A}$ of current, power factor $\operatorname{Cos} \theta=0,8$.

$\mathrm{Y}=\frac{I_{n l}}{V_{n l}}$

$\mathrm{Y}=\mathrm{G}+\mathrm{jB}$

$\mathrm{R}_{\mathrm{C}}=\frac{1}{\mathrm{G}}$

$\mathrm{X}_{\mathrm{m}}=\frac{1}{\mathrm{~B}}$

\section{Block Rotor Test}

Block rotor tests are performed to fulfill the needs of the equivalent circuit parameters of an induction motor. That X2 and R2 values conected in the series equivalent 
circuit. In the rotor block tests the results obtained voltage $16 \mathrm{~V}$, current 7A, and power factor $=0.92$

$\mathrm{Z}_{\mathrm{br}}=\frac{V_{b r}}{I_{b r} \sqrt{3}}$

$\mathrm{Z}_{\mathrm{br}}=\mathrm{R}_{\mathrm{br}}+\mathrm{j} \mathrm{X}_{\mathrm{br}}$

$\mathrm{R}_{2}^{\prime}=\mathrm{R}_{\mathrm{br}}-\mathrm{R}_{1}$

$\mathrm{X}_{\mathrm{br}}=\mathrm{X}_{1}+\mathrm{X}_{2}$,

With estimation that $\mathrm{X}_{1}=\mathrm{X}_{2}$,

\section{Motor Equivalent Circuit}

After all parameters has obtained, then equivalent circuit can be arranged, figure 12 shows the single flux axial one stator-one rotor induction motor equivalent circuit.

\section{E. Curve Characteristic of Torque Vs Velocity}

Curve of torque vs velocity is using to known caharcteristic of the torque changing to velocity. With this curve the performance and characteristic of power output motor can be know. Curve of torque vs velocity can be determine from differential of torque equation from equivalen circuit motor.

$$
V_{\text {thev }}=\frac{X_{m}}{\sqrt{R_{1}^{2}+\left(X_{1}+X_{m}\right)^{2}}} V_{1}
$$

Because $\mathrm{Xm}>>\mathrm{X} 1$ and $\mathrm{Xm}+\mathrm{X} 1>>\mathrm{R} 1$ then

$$
R_{\text {thev }}=R_{1}\left(\frac{X_{m}}{X_{1}+X_{m}}\right)^{2}
$$

$\mathrm{X}_{\text {thev }} \approx \mathrm{X}_{1}$

$$
\tau_{\text {ind }}=\frac{3 V_{\text {thev }}{ }^{2} \cdot R_{2} / s}{\omega_{\text {sync }}\left[\left(R_{\text {thev }}+R_{2} / s\right)^{2}+\left(X_{\text {thev }}+X_{2}\right)^{2}\right]}
$$

After get the torque equation, curve of torque vs velocity can be made. This curve made by insert value of slip(s) begin from 0 to 1 , the result of the curve shown below

Depending of characteristic curve torque vs velocity, it gained the maximum torque $0,79 \mathrm{Nm}$ at slip 0,07 or $7 \%$. The determined curve from measuring is with nominal voltage per-phase 15 Volt, maximum current 7A. Thus power input and output in this motor can be compared.

$$
\begin{aligned}
& \mathrm{Pin}=\sqrt{ } 3 . \mathrm{V}_{\text {ph-ph. }} \mathrm{I} \cdot \operatorname{Cos} \Theta \\
& \mathrm{P}_{\text {out }}=\mathrm{P}_{\text {mekanik }}=\tau \omega
\end{aligned}
$$

thus the efficiency, $\eta=\frac{\text { Pout }}{\text { Pin }} \times 100 \%$

\section{CONCLUSION}

1. Prototype of one stator-one rotor axial flux induction motor that has been made has total length dimensions $66 \mathrm{~mm}$ and outer diameter $200 \mathrm{~mm}$. Motor is made from commercially available material that is steel types St 37. By using this axial flux system, induction motor which formed from 2 pieces disc will has smaller dimension than common induction motor (radial flux), so it will very suitable when applied as a driver in electric vehicles.

2. No-load test will conducted at applied voltage of 15 volt, this axial flux induction motor can operated in ideal speed that is $1366 \mathrm{rpm}$ (slip 9\%), with flowing current 5,1 A.

3. Equivalent circuit of induction motor obtained from some following testing. With DC voltage test, the stator resistance ( $\mathrm{R} 1=1,14 \mathrm{ohm})$ is obtained, in noload test will obtained core losses parameter (Rc $=2,13 \mathrm{ohm})$ and the magnetizing reactance $(\mathrm{Xm}=$ 2,85 ohm). In locked-rotor test will obtained leakage reactance value $(\mathrm{X} 1=0,26 \mathrm{ohm}, \mathrm{X} 2=0,26 \mathrm{ohm})$, and rotor resistance ( $\mathrm{R} 2=0,07 \mathrm{ohm})$.

4. Based on torque vs. speed curve analysis, shown that the maximum torque is $0.79 \mathrm{Nm}$ at speed $146.01 \mathrm{rad}$ /s, so that the maximum output power is 115.34 watts. Starting torque is $0,19 \mathrm{Nm}$.

\section{REFERENCES}

[1]. Chapman. J. Stephen, "Electric Machine Fundamentals", McGraw-Hill, Fourth Edition

[2]. Du-Bar Christian,"Design of an axial flux machine for an inwheel motor application", Master of Science Thesis, Chalmers University of Technology, Goteborg, Sweden, 2011

[3]. Jacobson.Mark Z,"Review of solution to global warming, air pollution, and energy security”,Energy \& Environmental Science, www.rsc.org/ees, Desember 2008.

[4]. MIT Electric Vehicle Team,’Technology, Challenges , and the Future of Electric Drive”,web.mit.edu, April 2008.

[5]. M. Valtonen, A. Parviainen and J. PyrhOnen, "Influence of the Air-Gap Length to the Performance of an Axial-Flux Induction Motor", Proceedings of the 2008 International Conference onElectrical Machines, pp. 1-5, 2008.

[6]. M. Valtonen, "Performance Characteristics of an Axial-Flux Solid-Rotor-Core Induction Motor”, Phd thesis, Lappeenranta University of Technology, Lappeenranta, Finland, 2007.

[7]. NASIRI-GHEIDARI Zahra, LESANI Hamid,” A survey on Axial Flux Induction Motor”, University of Teheran.

[8]. Pyrhonen.J, Jokinen.T, Hrabovcova.V, ”Design of Rotating Electrical Machines", Department of Electrical Engineering, Lappeenranta University of Technology Finland, John Wiley \& Sons, UK, 2008

[9]. VTU Learning, “Design of Induction Motor”, elearning.vtu.ac.in/ELE1525.html. 
a)

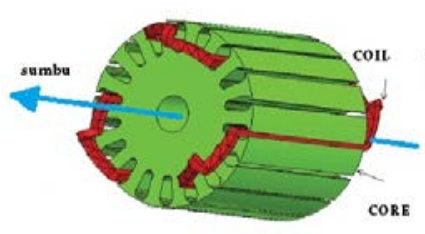

b)

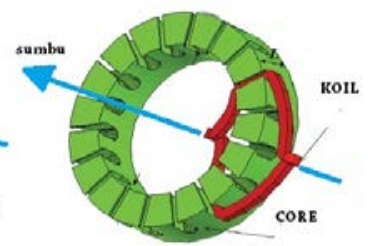

Figure 1. (a) Rotor construction and radial flux directions RFIM. (b) Stator construction and axial flux direction
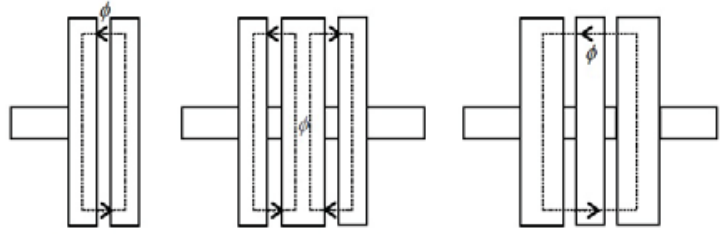

Figure 2. AFIM motor types. a) Single stator - single rotor. b) single stator-double rotor. c) double stator-single rotor

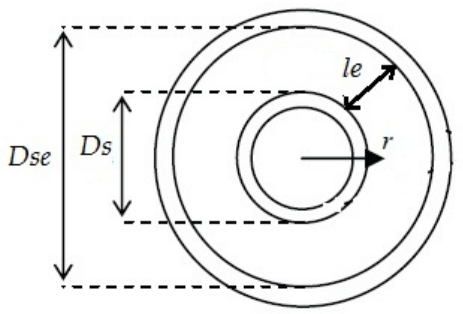

Figure 3. Sectional AFIM

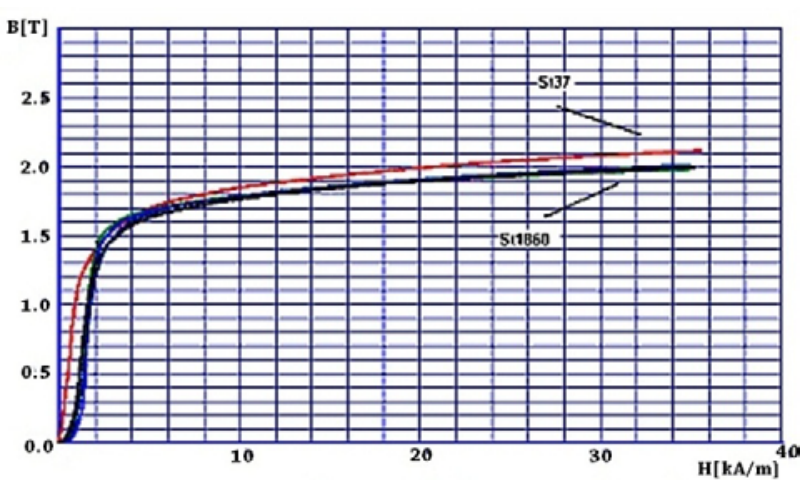

Figure 4. Kurva magnetisasi material St37

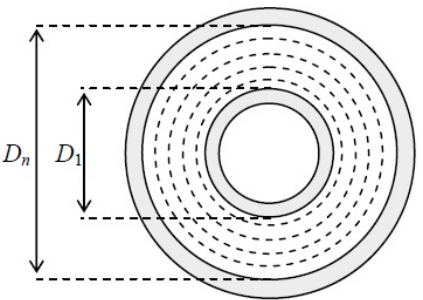

Figure 5. The distribution area of the stator and rotor

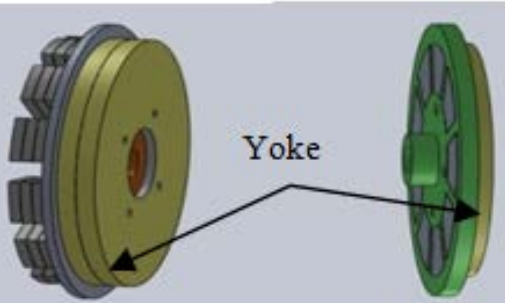

(a)

(b)

Figure 6. (a) Stator yoke, (b) rotor yoke

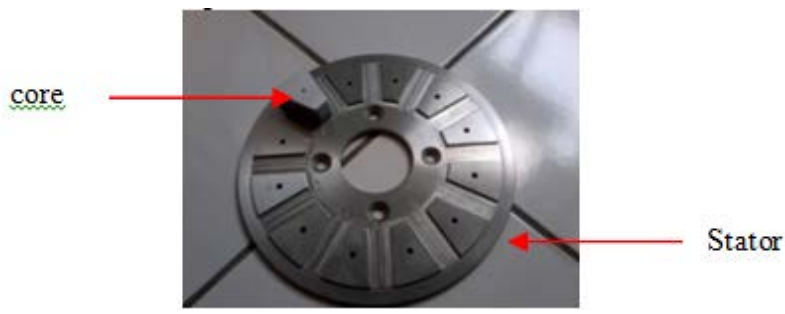

Figure 7.Stator Production

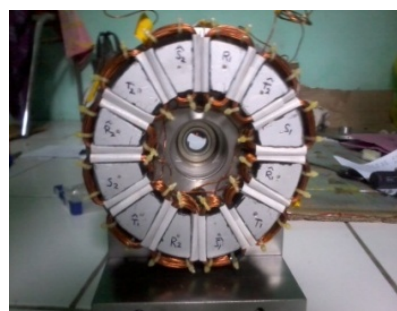

Figure 8.Stator with the winding

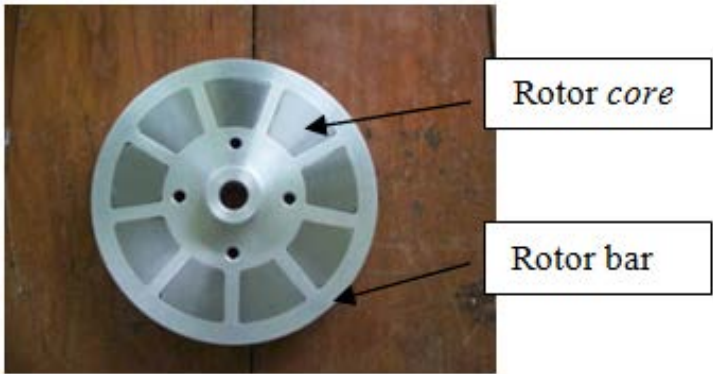

Figure 9. Rotor construction

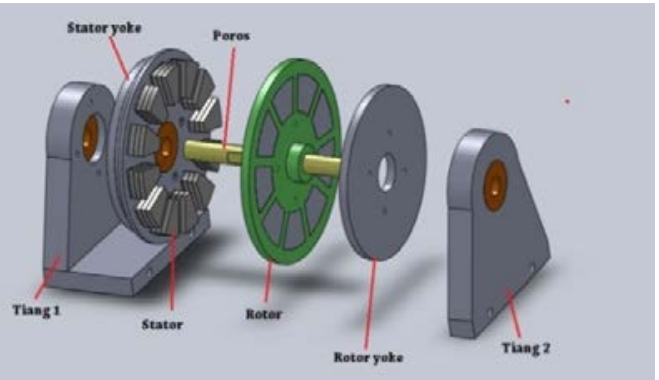

Figure 10. the arrangement of Assembly motor

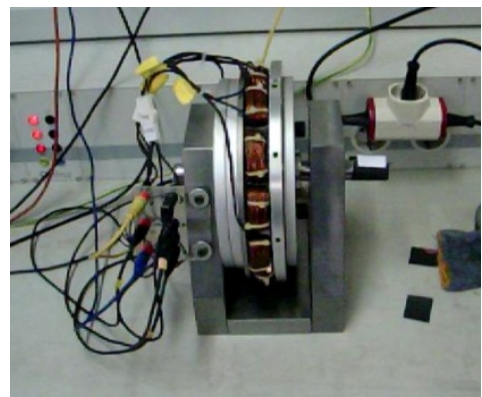

Figure 11. No-Load Test

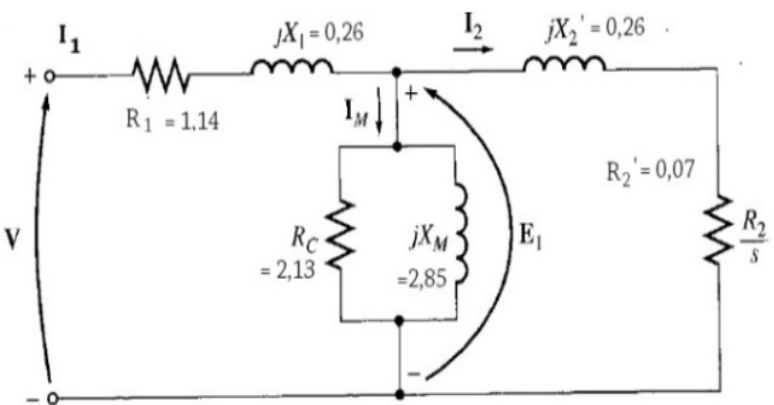

Figure 12. Equivalent circuit of the axial fluxmotor test results 


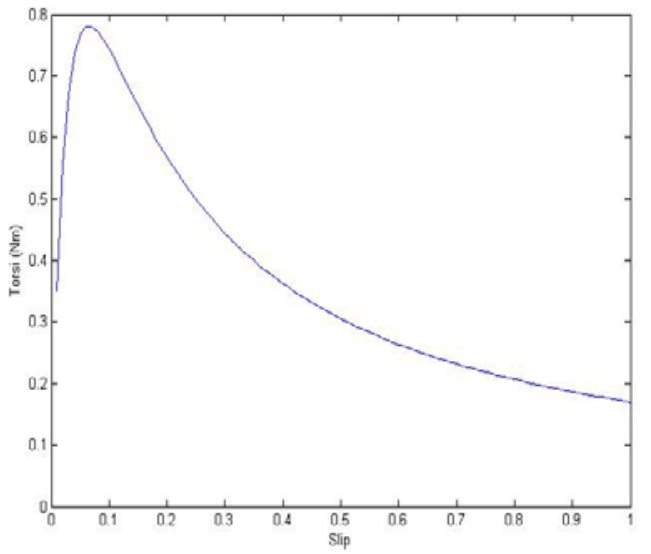

Figure 13. Kurva karakteristik Torsi vs Kecepatan

TABLE 1.

ST37 CONSTITUENT MATERIAL COMPOSITION MIXTURE IN (\%) Material Number 1.0037 - ST37-2/S235JR

\begin{tabular}{lllllllll} 
C & Si & Mn & P & S & Cr & Mo & Ni & N \\
\hline Max & Max & Max & Max & Max & - & - & - & Maks \\
0,17 & 0,30 & 1,40 & 0,045 & 0,045 & & & & 0,009
\end{tabular}

TABEL 2.

CALCULATION RESULTS OF FLUX DENSITY AT STATOR CORE

\begin{tabular}{rcrr}
\hline \hline No & $\begin{array}{c}\text { Width of stator } \\
\text { slot }(\mathrm{m})\end{array}$ & $\begin{array}{r}\text { Distance between } \\
\text { stator slot }(\mathrm{m})\end{array}$ & B in core $(\mathrm{T})$ \\
\hline 1 & 0.015 & 0.027213333 & 1.336899563 \\
2 & 0.015 & 0.029306667 & 1.229077353 \\
3 & 0.015 & 0.0314 & 1.148780488 \\
4 & 0.015 & 0.034016667 & 1.073269062 \\
5 & 0.015 & 0.036633333 & 1.016024653 \\
6 & 0.015 & 0.03925 & 0.971134021 \\
7 & 0.015 & 0.041866667 & 0.934987593 \\
8 & 0.015 & 0.044483333 & 0.905257207 \\
9 & 0.015 & 0.0471 & 0.880373832 \\
\hline \hline
\end{tabular}

TABLE 3.

\begin{tabular}{cccc}
\multicolumn{4}{c}{ THE CALCULATION RESULT OF A FLUX DENSITY IN ROTOR CORE } \\
\hline No & $\begin{array}{c}\text { Width a rotor slot } \\
(\mathrm{m})\end{array}$ & $\begin{array}{c}\text { Width between a } \\
\text { slot }(\mathrm{m})\end{array}$ & B in core $(\mathrm{T})$ \\
\hline 1 & 0.01 & 0.036284444 & 0.828271897 \\
2 & 0.01 & 0.039075556 & 0.806358912 \\
3 & 0.01 & 0.041866667 & 0.788284519 \\
4 & 0.01 & 0.045355556 & 0.769704588 \\
5 & 0.01 & 0.048844444 & 0.754462243 \\
6 & 0.01 & 0.052333333 & 0.741732283 \\
7 & 0.01 & 0.055822222 & 0.730940834 \\
8 & 0.01 & 0.059311111 & 0.721676431 \\
9 & 0.01 & 0.0628 & 0.713636364 \\
\hline
\end{tabular}

